\title{
Testing And Treating Helicobacter Pylori Infection
}

\author{
Dr James Li Weiquan, Dr Christopher Jen Lock Khor
}

\begin{abstract}
Helicobacter pylori (H. pylori) is an important pathogen in the stomach which can cause chronic inflammation, predisposing patients to peptic ulcer disease. It is also a class I human carcinogen, increasing the risk of gastric carcinoma. Eradication of $\boldsymbol{H}$. pylori has been shown to be effective in the prevention of peptic ulcer disease as well as gastric carcinoma. Singapore is an intermediate-risk area for gastric cancer, and the seroprevalence of $H$. pylori infection is 31 percent. Testing for $\boldsymbol{H}$. pylori consists of non-invasive tests such as $H$. pylori serology, stool antigen assay, and the urea breath test, as well as invasive tests requiring oesophago-gastro-duodenoscopy (OGD) and biopsies for the rapid urease test, histology, and cultures. Stool antigen assay represents a more accurate non-invasive outpatient test for $\mathrm{H}$. pylori at slightly increased cost in the primary care setting, as positive $\boldsymbol{H}$. pylori serology does not necessarily imply active infection. Triple therapy remains an effective first-line eradication treatment in Singapore from studies of $H$. pylori resistance locally. Treatment failures should be retreated with quadruple therapy or other strategies such as concomitant therapy, hybrid therapy and sequential therapy.
\end{abstract}

Keywords: Helicobacter pylori; Testing; Treatment; Non-invasive Tests; Resistance;

SFP20 I 7; 43(2): 52-54

\section{IMPORTANCE OF HELICOBACTER PYLORI INFECTION}

Helicobacter pylori (H. pylori) is a bacterium that is found in the stomach and is estimated to be present in approximately half of the world's population. It is believed to be spread by consuming food and water contaminated by faecal matter. Infection of the protective lining of the stomach by $H$. pylori leads to release of enzymes and toxins, which in turn activate the immune system, resulting in damage to cells in the stomach and duodenum.

The chronic inflammation induced by $H$. pylori has been implicated in gastric cancer, as the chronically inflamed gastric

\section{JAMES LI WEIQUAN}

Senior Resident, Gastroenterology and Hepatology,

Singapore Health Services. Department of Gastroenterology

and Hepatology, Singapore General Hospital

\section{CHRISTOPHER JEN LOCK KHOR}

Senior Consultant \& Head / Department of

Gastroenterology \& Hepatology

Director, Endoscopy Centre

Singapore General Hospital mucosa may progress through the premalignant stages of gastric atrophy, intestinal metaplasia, dysplasia, and finally adenocarcinoma. ${ }^{1} H$. pylori is recognised by the International Agency for Research on Cancer (IARC) as a class 1 human carcinogen. ${ }^{2}$ It is also associated with peptic ulcer disease.

In Singapore, which is an intermediate-risk area for gastric cancer, the seroprevalence rate of $H$. pylori infection is 31 percent. ${ }^{3,4}$ Successful eradication of $H$. pylori has been shown to be important for primary and secondary prevention of peptic ulcer disease, as well as gastric cancer. The Shandong Intervention Trial demonstrated a significant decrease in gastric cancer incidence by 39 percent during a follow-up period which extended 14.7 years after eradication of $H$. pylori. ${ }^{5}$ A large observational study conducted on Matsu island in Taiwan also showed a decline in the 5-year incidence of gastric cancer from 40.3 per 100,000 person years to 30.4 per 100,000 person years following successful eradication of $H$. pylori. ${ }^{6}$ These findings have also been supported by animal and population-based studies, and eradication of $H$. pylori infection has also been shown to decrease the incidence of metachronous gastric cancer following endoscopic resection of early gastric cancer. ${ }^{7}$

\section{TESTING FOR H. PYLORI INFECTION}

These consist of non-invasive tests such as $H$. pylori serology, stool antigen assay, and the urea breath test, as well as invasive tests requiring oesophago-gastro-duodenoscopy (OGD) and biopsies for the rapid urease test, histology, and cultures. This review will focus primarily on non-invasive testing, as it is more applicable to the primary care setting. It is important to bear in mind that the direct tests for $H$. pylori (i.e. all tests except for serology) require cessation of proton pump inhibitor (PPI) therapy at least 2 weeks before testing, to prevent false negative results. This is necessary as PPIs have intrinsic anti-helicobacter activity which will suppress bacterial count in the stomach.

\section{Serology $8-11$}

This is a laboratory-based test utilising ELISA technology to detect immunoglobulin $\mathrm{G}$ ( $\mathrm{IgG}$ ) antibodies to $H$. pylori. Its advantages lie in the fact that it is non-invasive, relatively inexpensive and well-suited to primary care practice. $H$. pylori serology also has the added advantage of not being affected by PPI therapy (see above).

However, the disadvantage lies in the need for local validation, which may not be practical. Moreover, although studies have shown universally high sensitivity ranging from 90 to 100 percent, serological testing for $H$. pylori has variable accuracy for detection of active infection. In areas with an $H$. pylori incidence of less than 20 percent, the positive predictive value for $H$. pylori serology is only 50 percent. As such, the guidelines recommend testing with stool antigen assay or urea breath test in these low-prevalence populations, rather than with $H$. pylori serology. 
The interpretation of $H$. pylori serology following eradication therapy is even more complicated, as illustrated by a study which showed that 40 percent of subjects who had successful eradication of $H$. pylori still had detectable $H$. pylori antibodies 18 months after therapy was administered. Hence, $H$. pylori serology is unsuitable for documenting eradication of $H$. pylori infection.

\section{Stool Antigen Assay ${ }^{12-16}$}

This test utilises the detection of antigens from $H$. pylori in stool, and has a sensitivity and specificity of approximately 94 percent and 92 percent respectively. It is also useful for documenting eradication of $H$. pylori infection, with a sensitivity and specificity of 90 percent and 95 percent respectively, 4 weeks after completion of eradication therapy.

The main disadvantage of stool antigen assay is that a false negative rate of up to 25 percent may occur with PPI use. In addition, the stool antigen assay can also be falsely positive in the setting of acute upper gastrointestinal bleeding as a result of cross reaction with blood constituents.

A decision analysis study exploring the cost effectiveness of multiple testing strategies for $H$. pylori showed that in areas with low to intermediate prevalence of $H$. pylori, the stool antigen assay offers better accuracy (93\%) compared to $H$. pylori serology (80-82\%) at only a slight increase in cost.

Hence, the stool antigen assay is recommended over serological testing for detection of active $H$. pylori infection.

\section{Urea Breath Test ${ }^{14,17,18}$}

This non-invasive test utilises the hydrolysis of urea by $H$. pylori to produce carbon dioxide and ammonia. The tagged carbon dioxide is detected in breath samples, indicating the presence of active $H$. pylori infection. Urea breath test has a sensitivity and specificity ranging from 88-95 percent and 95-100 percent respectively. Similar to stool antigen assay, it also has false negative findings when patients are on PPI at the time of testing, However, the false negative rates are higher than for the stool antigen assay, at 33 percent.

\section{Rapid Urease Test ${ }^{9,19}$}

The rapid urease test is an invasive test, where one or two pieces of tissue from gastric mucosal biopsies are placed in an agar well containing urea and a $\mathrm{pH}$ reagent. The urease in $H$. pylori cleaves the urea in the agar to produce ammonia. This results in a change in $\mathrm{pH}$, thereby causing the $\mathrm{pH}$ reagent to change colour.

The sensitivity and specificity of the rapid urease test are 90-95 percent and 95-100 percent respectively. The test may become positive an hour after testing, but waiting for $24 \mathrm{~h}$ before reading the test is recommended. False negative results may occur with use of PPI, antibiotics, or bismuth at the time of testing. Recent gastrointestinal bleeding may also result in false negative results.

\section{Histology}

This is where gastric mucosal specimens from biopsies are examined under microscopy with Giemsa or special immune stains to improve detection of $H$. pylori. Sampling error may occur due to differences in density of $H$. pylori at different sites in the stomach. In addition, there may also be inter-observer variability in the interpretation of the biopsy specimen.

\section{H. pylori Cultures}

These are not routinely recommended. $H$. pylori cultures are useful for the setting of refractory disease with suspected antibiotic resistance (see next section on Treatment of $H$. pylori Infection).

\section{TREATMENT OF H. PYLORI INFECTION}

Guidelines recommend that eradication regimens should be based on the best locally available regimen, and only regimens which can reliably produce eradication rates of more than or equal to 90 percent in a particular population should be used for empirical treatment. ${ }^{20}$ An earlier study by Graham et $\mathrm{al}^{21}$ showed that for the efficacy of triple therapy with Amoxicillin, Clarithromycin and a PPI to fall below this threshold of 90 percent, the resistance rates to Clarithromycin would be around 15-20 percent. Indeed, antibiotic resistance involving Clarithromycin, Levofloxacin and Metronidazole, common antibiotics used in triple-therapy regimens for eradication of $H$. pylori infection, have been increasing over the years and, in many countries, have exceeded 20 percent. ${ }^{22}$

Fortunately, a recent study in Singapore showed that the $H$. pylori resistance rates to Clarithromycin and Levofloxacin, although displaying an increasing trend, are still safely below 20 percent. ${ }^{23}$ Amoxicillin, which forms the backbone of most triple-therapy regimens, has low rates of resistance reported worldwide.

Triple therapy usually consists of 2 antibiotics and a PPI. One of the antibiotics is Amoxicillin, administered at a dose of $1 \mathrm{~g}$ twice a day. The second antibiotic is usually either Clarithromycin dosed at 500mg twice a day or Metronidazole $500 \mathrm{mg}$ twice a day. The PPI is similarly dosed twice daily. In the context of retreatment, the second antibiotic is sometimes Levofloxacin $500 \mathrm{mg}$ twice daily. Alternatively, for retreatment following failure of triple therapy or in the context of penicillin allergy, a bismuth-based quadruple therapy consisting of a PPI, bismuth, metronidazole and tetracycline may be used. Regardless of the regimen chosen, the total duration of treatment should be at least 10 to 14 days to improve eradication rates. ${ }^{24}$ Other strategies to overcome resistance in cases of treatment failure include concomitant therapy, hybrid therapy and sequential therapy.

\section{CONCLUSION}

H. pylori is an important pathogen and should be eradicated if detected. Serological testing for $H$. pylori, while simple to 
perform and cheaper in an outpatient setting, may not yield accurate findings upon which treatment decisions can be made unless in the right clinical context. The stool antigen assay represents a more accurate non-invasive outpatient test for $H$. pylori, at a slightly increased cost.

Author Contributorship: Weiquan James Li performed the research and wrote the paper; Christopher Jen Lock Khor provided writing advice and supervised the paper.

The authors declare that they have no conflict of interest in relation to this article.

\section{REFERENCES}

I. Correa P. Human gastric carcinogenesis: a multistep and multifactorial process-First American Cancer Society Award Lecture on Cancer Epidemiology and Prevention. Cancer Res.

1992;52:6735-40. PMID: I458460.

2. International Agency for Research on Cancer. Infection with Helicobacter pylori. IARC Monogr Eval Carcinog Risks Hum. 1994;61: I77-240. PMID: 77I5070.

3. Fock KM, Ang TL. Epidemiology of Helicobacter pylori infection and gastric cancer in Asia. J Gastroenterol Hepatol. 2010;25:479-86. doi: |0.1 I I I/j. I440-1746.2009.06/88.

4. Fock KM. Review article: the epidemiology and prevention of gastric cancer. Aliment Pharmacol Ther. 2014;40:250-60. doi:

I0.1 III/apt. I28I4.

5. Ma JL, Zhang L, Brown LM, Li JY, Shen L, Pan KF, et al. Fifteen-year effects of Helicobacter pylori, garlic, and vitamin treatments on gastric cancer incidence and mortality. J Natl Cancer Inst. 2012;104:488-92. doi: 10.1093/jnci/djs003.

6. Lee YC, Chen THH, Chiu HM, Shun CT, Chiang H, Liu TY, et al. The benefit of mass eradication of Helicobacter pylori infection: a community-based study of gastric cancer prevention. Gut. 2013;62:676-82. doi: I0.1 I36/gutjnl-2012-302240.

7. Li JW, Tan MT, Ang TL, Teo EK. Chemoprevention trials of GI cancers in Asia. Best Pract Res Clin Gastroenterol. 2015;29:967-78. doi: 10.1016/j.bpg.2015.09.014.

8. Malfertheiner P, Megrad F, O'Morain C, Bazzoli F, El-Omar E, Graham D, et al. Current concepts in the management of Helicobacter pylori infection: the Maastricht III Consensus Report. Gut.

2007;56:772-8I. doi: 10.1 I36/gut.2006.101634

9. Chey WD, Wong BC, Practice Parameters Committee of the American College of Gastroenterology. American College of Gastroenterology guideline on the management of Helicobacter pylori infection. Am J Gastroenterol. 2007; 102:1808-25. doi:

I0.1 III/j.1572-0241.2007.01393.

10. Talley NJ, Vakil NB, Moayyedi P. American gastroenterological association technical review on the evaluation of dyspepsia.

Gastroenterology. 2005; 129:1756-80. doi:

10.1053/j.gastro.2005.09.020.

II. Feldman F, Cryer B, Lee E, Peterson WL.. Role of seroconversion in confirming cure of Helicobacter pylori infection. JAMA. 1998;280:363-5. PMID: 9686554.

12. Vaira D, Malfertheiner P, Mégraud F, Axon AT, Deltenre M, Hirschl AM, et al. Diagnosis of Helicobacter pylori infection with a new non-invasive antigen-based assay. HpSA European study group. Lancet. 1999;354:30-3. PMID: 10406362.

13. Manes G, Balzano A, laquinto G, Ricci C, Piccirillo MM, Giardullo $\mathrm{N}$, et al. Accuracy of the stool antigen test in posteradication assessment of Helicobacter pylori infection. Dig Dis Sci. 200I;46:2440-4. PMID: II 713949.

14. Bravo LE, Realpe JL, Campo C, Mera R, Correa P. Effects of acid suppression and bismuth medications on the performance of diagnostic tests for Helicobacter pylori infection. Am J Gastroenterol.

1999;94:2380-3. doi: 10.1 III/j.1572-0241.1999.0136I.

15. van Leerdam ME, Vreeburg EM, Rauws EA, Geraedts AA, Tijssen JG, Reitsma JB, et al. Acute upper GI bleeding: did anything change? Time trend analysis of incidence and outcome of acute upper $\mathrm{Gl}$ bleeding between 1993/1994 and 2000. Am J Gastroenterol. 2003;98: I494-9. doi: I0.1 I I I/j.1572-024I.2003.075। 7 .

16. Vakil N, Rhew D, Soll A, Ofman JJ. The cost-effectiveness of diagnostic testing strategies for Helicobacter pylori. Am J Gastroenterol. 2000;95:169I-8. doi: I0.1 I I I/j.1572-024I.2000.02193. 17. Leide-Svegborn S, Stenstrom K, Olofsson M, Mattsson S, Nilsson LE, Nosslin B, et al. Biokinetics and radiation doses for carbon- 14 urea in adults and children undergoing the Helicobacter pylori breath test. Eur J Nucl Med. 1999;26:573-80. PMID: 10369942.

18. Howden CW, Hunt RH. Guidelines for the management of Helicobacter pylori infection. Ad Hoc Committee on Practice Parameters of the American College of Gastroenterology. Am J Gastroenterol. 1998;93:2330-8. doi: 10.1 I I I/j.I572-024I.1998.00684. 19. Laine L, Lewin D, Naritoku W, Estrada R, Cohen H. Prospective comparison of commercially available rapid urease tests for the diagnosis of Helicobacter pylori. Gastrointest Endosc. 1996;44:523-6. PMID: 8934I55.

20. Sugano K, Tack J, Kuipers EJ, Graham DY, El-Omar EM, Miura S, et al. Kyoto global consensus report on Helicobacter pylori gastritis. Gut. 20I5;64:1353-67. doi: 10.1 I36/gutjnl-20I5-309252.

21. Grahiam DY, Fischbach L. Helicobacter pylori treatment in the era of increasing antibiotic resistance. Gut. 2010;59: 1 143-53. doi: 10.1 |36/gut.2009.192757

22. Thung I, Aramin H, Vavinskaya V, Gupta S, Park JY, Crowe SE, et al. Review article: the global emergence of Helicobacter pylori antibiotic resistance. Aliment Pharmacol Ther. 2016;43:5 I4-33. doi:

I0.I I I I/apt. 13497

23. Ang TL, Fock KM, Ang D, Kwek ABU, Teo EK, Dhamodaran S. The changing profile of Helicobacter pylori antibiotic resistance in Singapore: a I5-year study. Helicobacter. 2016;21:26I-5. doi: I0.1 I I I/hel. I229I.

24. Yuan Y, Ford AC, Khan KJ, Gisbert JP, Forman D, Leontiadis GI, et al. Optimum duration of regimens for Helicobacter pylori eradication. Cochrane Database Syst Rev. 2013;(I2):CD008337. doi: 10.1002/1465/858

\section{LEARNING POINTS}

- H. pylori is an important pathogen and should be eradicated if detected.

- Serological testing, while simple to perform and relatively cheap in an outpatient setting, may not yield accurate findings upon which treatment can be based unless in the correct clinical context.

- The stool H. pylori antigen assay represents a more accurate non-invasive, outpatient test at a marginally increased cost. 